
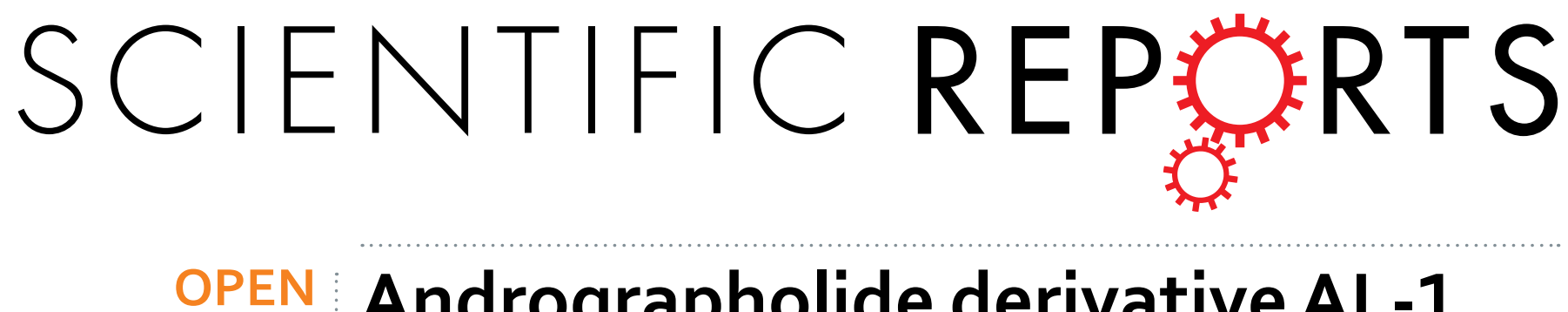

\title{
Andrographolide derivative AL-1 ameliorates TNBS-induced colitis in mice: involvement of NF-KB and \\ PPAR- $\gamma$ signaling pathways
}

Received: 17 March 2016

Accepted: 21 June 2016

Published: 20 July 2016
Yali Yang*, Hui Yan", Mei Jing, Zaijun Zhang, Gaoxiao Zhang, Yewei Sun, Luchen Shan, PeiYu, Yuqiang Wang \& Lipeng $\mathrm{Xu}$

Andrographolide is a traditional herb medicine, widely used in Asia for conditions involving inflammation. The andrographlide-lipoic acid conjugate, AL-1, has been found being able to alleviate inflammation in our previous reports. Although the anti-inflammatory activity of AL-1 contributes to its cytoprotective effects, whether AL-1 can improve inflammatory bowel disease (IBD) and the underlying mechanisms of its action remain largely unknown. In this study, we investigated the anti-inflammatory effects of AL-1 in C57BL/6 mice with trinitrobenzenesulfonic acid (TNBS)-induced colitis. The body weight loss and length change of colon after TNBS instillation were more severe than those in normal mice. AL-1 treatment led to significant reductions in disease activity index (DAl), macroscopic score and colon mucosa damage index (CMDI) associated with TNBS administration. AL-1 inhibited the inflammatory response via lowering the level of inflammatory cytokines and myeloperoxidase (MPO) activity. AL-1 attenuated the expression of $\mathrm{p}-\mathrm{p} 65, \mathrm{p}-\mathrm{I} \mathrm{KB} \alpha$ and $\mathrm{COX}-2$ in the colitis mice. The alleviation of colon injury by AL-1 treatment was also evidenced by the increased expression of PPAR- $\gamma$. These results indicated that AL-1 could protect intestinal tract from the injury induced by TNBS in mice, suggesting that AL-1 may have potential in treatment for IBD.

Inflammatory bowel disease (IBD), which consists of ulcerative colitis and Crohn's disease, refers to immunologically mediated inflammatory disorder of the gastrointestinal tract ${ }^{1}$. IBD afflicts nearly 1.5 million Americans and 2.2 million people in Europe and several hundred thousands more worldwide ${ }^{2,3}$. However, the precise pathogenesis of IBD is not well understood. There is growing evidence that the delicate balance among the microbiota, the intestinal epithelium and the immune system sustains the health of gastrointestinal tracts ${ }^{4}$. Once the homeostasis breaks down and shifts to the pro-inflammatory side, hyperactive immune cells secrete the pro-inflammatory cytokines including TNF- $\alpha$, IL- $1 \beta$ and IL- 6 through the activation of regulatory mechanisms such as the NF- $\kappa B$ and PPAR- $\gamma$ pathways ${ }^{5-7}$. These signaling cascades would increase people's susceptibility to IBD and eventually precipitate the chronic inflammatory pathology found in the disease. NF- $\kappa B$, comprising the p 65 and p50 subunits, plays a crucial role in controlling inflammatory response of immune disease ${ }^{8}$. Therefore, blockade of NF- $\kappa B$ activation would be a robust therapeutic intervention for IBD. Likewise, the activation of PPAR- $\gamma$ would alleviate the inflammatory processes of $\mathrm{IBD}^{7}$.

There are intense demands of more optimal medical therapies for IBD accompanying with the understanding of the pathogenesis of IBD. In recent years, there are extensive research on using herbal medicines as potential agents for $\mathrm{IBD}^{9-11}$. A. paniculate leaves are rich in the andrographolide and are widely employed in folk medicine as antibacterial, anti-asthmatic, antiviral, and neuroprotective and anti-inflammatory agents ${ }^{12-15}$. Andrographolide sulfonate, approved as an anti-inflammatory drug in China for year, has showed significant activity in TNBS-induced colitis in mice ${ }^{16}$. Likewise, alpha-lipoic acid has been identified as a potential remedy of IBD ${ }^{17-19}$. AL-1 (Fig. 1), an andrographolide-lipoic acid conjugate, has shown anti-inflammatory effects

Institute of New Drug Research and Guangzhou Key Laboratory of Innovative Chemical Drug Research in Cardiocerebrovascular Diseases, Jinan University College of Pharmacy, Guangzhou 510632, China. *These authors contributed equally to this work. Correspondence and requests for materials should be addressed to L.X. (email: xulipeng2000@163.com) 
<smiles>C=C1CCC2C(C)(CO)C(O)CCC2(C)[C@H]1C/C=C1/C(=O)OCC1O</smiles>

Andrographolid (Andro)<smiles>C=C1CCC2C(C)(CO)C(O)CCC2(C)[C@H]1CC=C1C(=O)OCC1OC(=O)CCCCC1CCSS1</smiles>

Andrographolid-lipoic acid (AL-1)<smiles>O=C(O)CCCCC1CCSS1</smiles>

Alpha lipoic acid (LA)

Figure 1. Structures of Andro, LA and AL-1.

in our previous studies ${ }^{15,20}$. In this study, we investigated the therapeutic effects and mechanisms of AL-1 in TNBS-induced colitis in mice.

\section{Results}

The anti-inflammatory effects of AL-1 in mice with TNBS-induced colitis. In order to examine whether AL-1 could improve the clinical symptoms of TNBS-induced colitis in mice, the clinical signs including weight changes, colon length, DAI score and macroscopic score were assessed. The significant weight loss, DAI score and macroscopic score and shortening colon length in model group manifested that colon instillation of TNBS resulted in a reproducible colitis in mice (Fig. 2A-F). As shown in Fig. 2B, AL-1 or mesalazine administration attenuated the declining of body weight which was observed in TNBS challenged mice. Treatment with AL-1 produced a significant improvement in colon length, DAI score and macroscopic score compared with those in the model group (Fig. 2B-E). Therefore, these data suggested that AL-1 ameliorated the severity of TNBSinduced injury in mice.

AL-1 diminished colonic histopathological changes. Based on the previous data, we then investigated whether AL-1 could alter histopathological damage in colons of mice with TNBS-induced colitis. The colon tissue from model group revealed typical characteristics of abnormal structure including loss of epithelial and goblet cells, crypt lesions and prominent transmural inflammatory cells infiltration in the intestine mucosa and submucosa (Fig. 3A). The degree of colitis was quantitatively evaluated using the scoring system described in materials and methods (Fig. 3B). Moreover, AL-1 improved the histopathological changes caused by TNBS.

AL-1 suppressed recruitment of immune-inflammatory cells. MPO activity, a biochemical maker for neutrophil influx, was assessed to detect the potency of AL-1 of resisting inflammatory cell infiltration. The alteration of MPO activity was consistent with the changes in histological score described before indicating that AL-1 drastically inhibited the pronounced damage induced by TNBS (Fig. 4).

Secretion of pro-inflammatory cytokines was down-modulated by AL-1. Next, we measured the effects of AL- 1 on the expression of pro-inflammatory cytokines TNF- $\alpha$, IL-1 $\beta$ and IL-6. As depicted in Fig. 5, TNBS instillation promoted the expression of TNF- $\alpha$, IL-1 $\beta$ and IL- 6 in mice. In contrast with the model group, AL-1 remarkably attenuated the levels of pro-inflammatory cytokines TNF- $\alpha$, IL- $1 \beta$ and IL- 6 .

AL-1 modulated the expression of COX-2, NF- $\kappa$ B and PPAR- $\gamma$. Furthermore, we investigated the possible role of AL-1 in the expression of COX-2, NF- $\kappa$ B and PPAR- $\gamma$ in mice with TNBS colitis (Fig. 6). Mice in the model group exhibited a tendency to up-regulate COX-2, p-p65 and p-I $\kappa \mathrm{B} \alpha$ expression. However, an attenuated trend was observed in the groups treated with AL-1. AL-1 administration increased the expression of PPAR- $\gamma$ which might act as an anti-inflammatory role in the progress of colitis (Fig. 6D). Together, the ability of AL-1 to modulate the expression of COX-2, NF- $\kappa B$ and PPAR- $\gamma$ conferred anti-inflammatory capacity to AL-1 in IBD. 


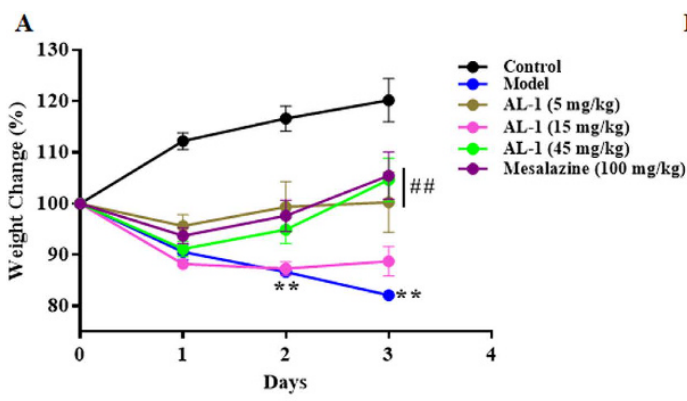

D

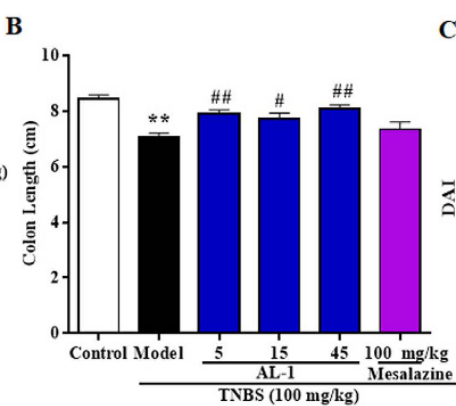

C

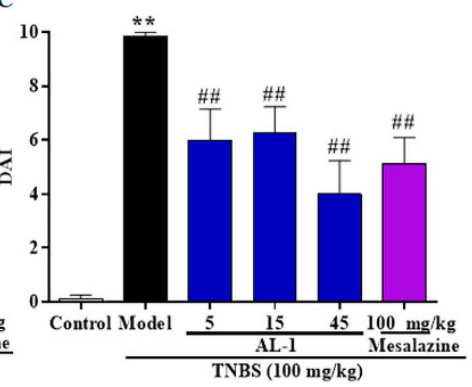

$\underline{\mathbf{E}}$

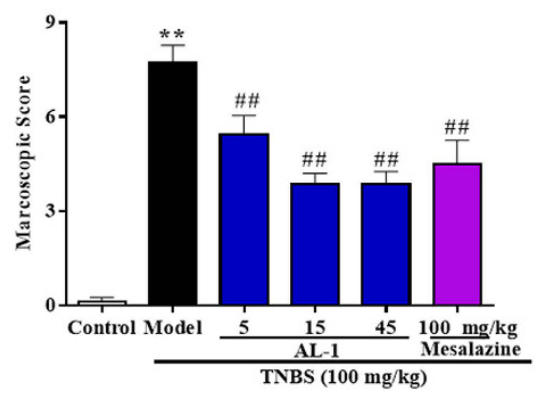

Figure 2. Effects of AL-1 on colitis induced by TNBS instillation in C57BL/6. (A) The time-course of body weight changes on day 3 after TNBS-induced colitis. (B) Effects of AL-1 and mesalazine on colon length of TNBS-induced colitis mice. (C) Disease activity index calculated as described in material and methods.

(D) Representative photograph of colons from day 3 after the induction of TNBS-colitis. (E) Macroscopic score. Mice were challenged with solvent or TNBS at day 0 and treated with control, AL-1 (5, 15 and $45 \mathrm{mg} / \mathrm{kg})$ or mesalazine $(100 \mathrm{mg} / \mathrm{kg})$ for days $0-3$. Body weight was measured daily throughout the experiment. Values were shown as the means \pm SEM, $\mathrm{n}=8$ for each group. ${ }^{* *} P<0.01$ vs control group, ${ }^{\#} P<0.05$ and ${ }^{\# \#} P<0.01$ vs mice treated with TNBS alone.

A
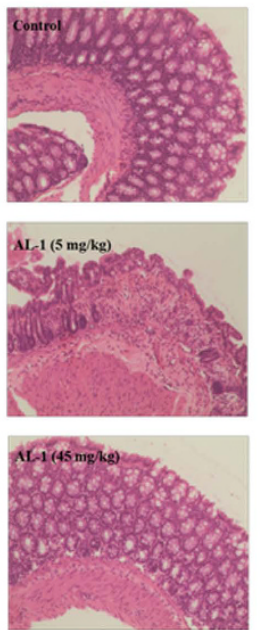
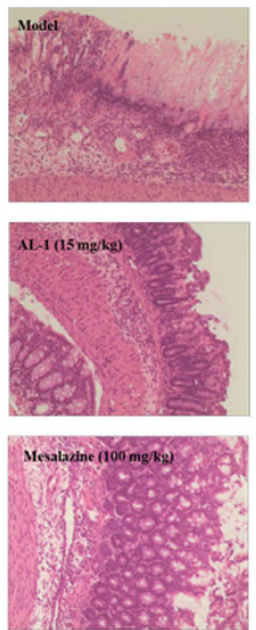

B

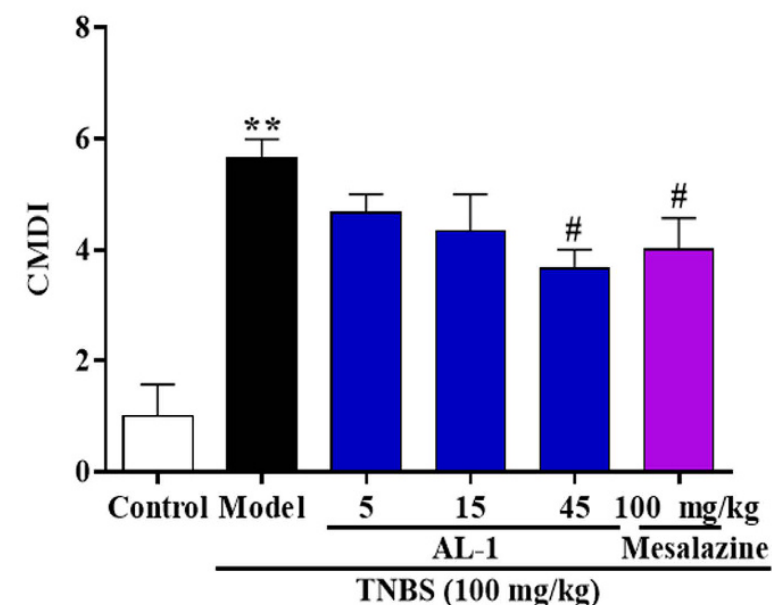

Figure 3. Effects of AL-1 on colonic histopathological changes. (A) Histological appearance of mice colonic mucosa after haematoxylin and eosin $(\mathrm{H} \& \mathrm{E})$ stain (original magnification $100 \times)$. (B) The score of colon mucosa damage index (CMDI) of mice. Mice were challenged with solvent or TNBS at day 0 and treated with control, AL-1 (5, 15 and $45 \mathrm{mg} / \mathrm{kg})$ or mesalazine $(100 \mathrm{mg} / \mathrm{kg})$ for days $0-3$. After sacrificed at day 3 , sections of the colon were collected, embedded in paraffin, and cut into $4 \mu \mathrm{m}$ of sections and stained with hematoxylin and eosin before examination. Values were shown as the means $\pm \mathrm{SEM}, \mathrm{n}=8$ for each group. $* * P<0.01$ vs control group, ${ }^{\# \#} P<0.05$ vs mice treated with TNBS alone.

\section{Discussion}

In this study, we demonstrated that AL- 1 could alleviate the severity and extent of colonic damage caused by TNBS in mice. AL-1 acts through down-regulating NF- $\kappa B$ pathway and up-regulating PPAR- $\gamma$ pathway to reduce 


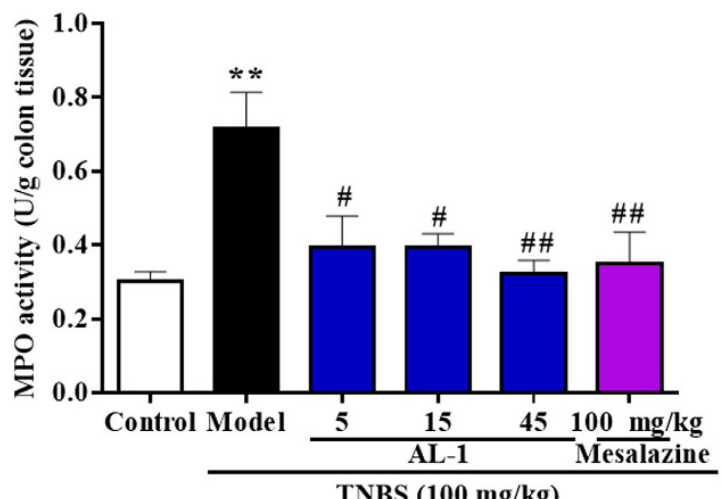

Figure 4. Effects of AL-1 on myeloperoxidase (MPO) activity in colonic tissues of mice. Mice were challenged with solvent or TNBS at day 0 and treated with control, AL-1 $(5,15$ and $45 \mathrm{mg} / \mathrm{kg})$ or mesalazine $(100 \mathrm{mg} / \mathrm{kg})$ for days $0-3$. Protein from colon tissue was extracted and MPO level was determined according to manufacturer's instructions. Values were shown as the means $\pm S E M, n=8$ for each group. $* * P<0.01$ vs control group, ${ }^{\#} P<0.05$ and ${ }^{\# \#} P<0.01$ vs mice treated with TNBS alone.

A

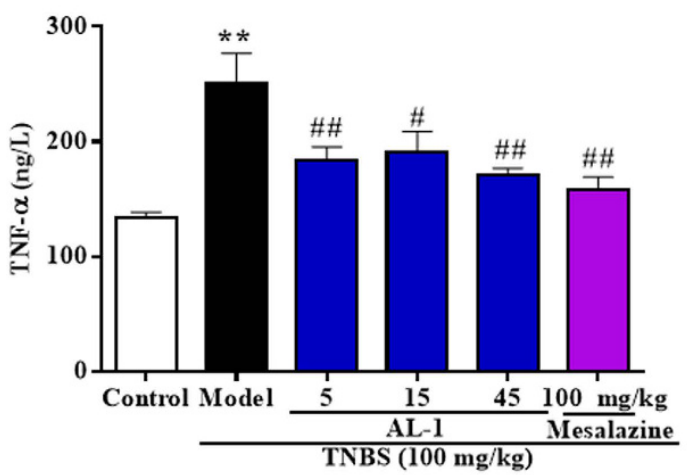

B

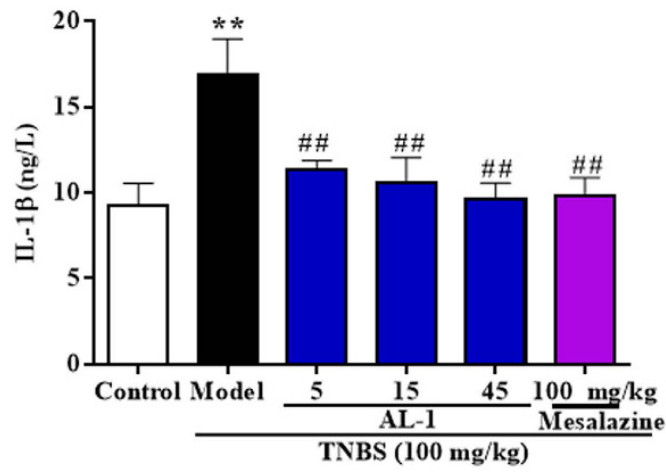

C

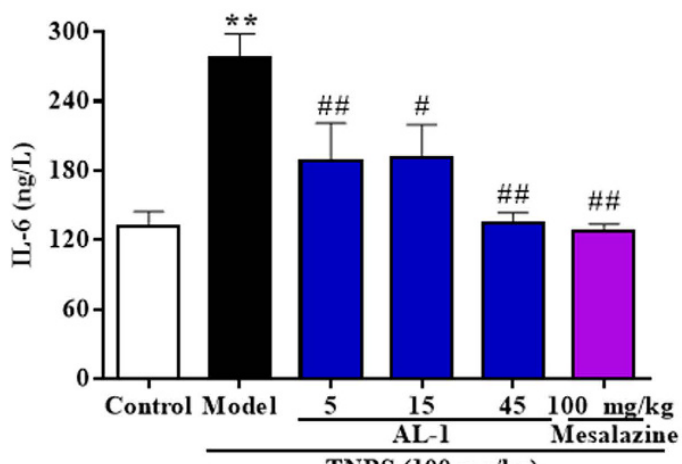

TNBS $(100 \mathrm{mg} / \mathrm{kg})$

Figure 5. Inhibitory effects of AL-1 on the pro-inflammatory cytokine production in serum level of mice. The production of (A) TNF- $\alpha$, (B) IL-1 $\beta$ and (C) IL-6, were assayed in colonic tissues of mice. Mice were challenged with solvent or TNBS at day 0 and treated with control, AL-1 $(5,15$ and $45 \mathrm{mg} / \mathrm{kg})$ or mesalazine $(100 \mathrm{mg} / \mathrm{kg})$ for days $0-3$. The TNF- $\alpha$, IL-1 $\beta$ and IL- 6 concentration in the serum level were determined by ELISA. Values were shown as the means \pm SEM, $\mathrm{n}=8$ for each group. ${ }^{* *} P<0.01$ vs control group, ${ }^{*} P<0.05$ and ${ }^{\# \# P}<0.01$ vs mice treated with TNBS alone. 
$\mathbf{A}$
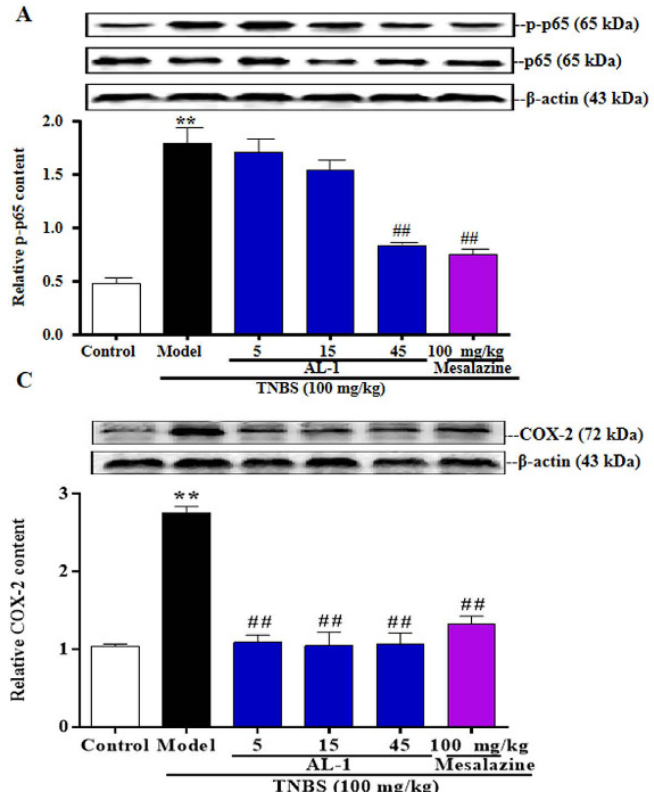
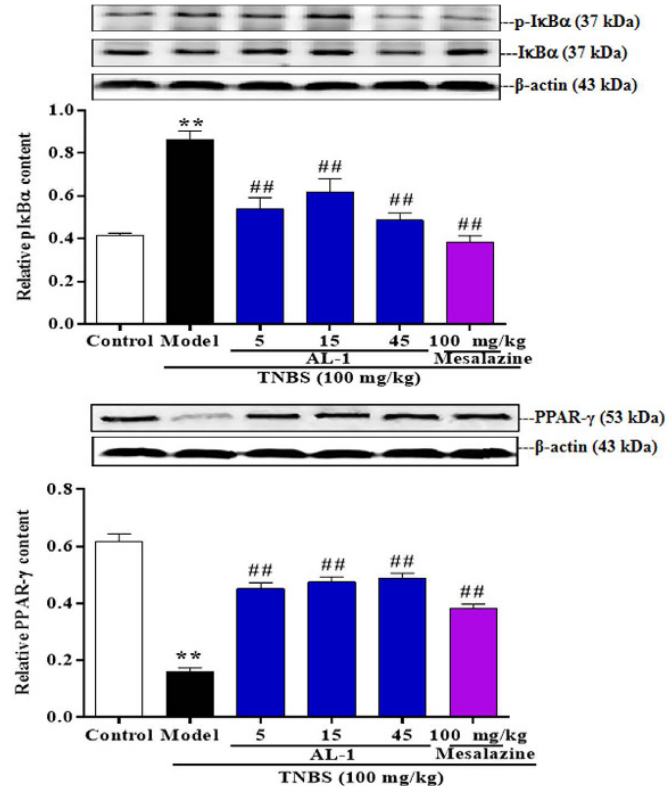

Figure 6. Effects of AL-1 on protein expression of COX-2, p-p65, p-I $\mathrm{BB} \alpha$ and PPAR- $\gamma$ in colon tissues. (AD) Mice were challenged with saline or TNBS at day 0 and treated with control, AL-1 (5, 15 and $45 \mathrm{mg} / \mathrm{kg})$ or mesalazine $(100 \mathrm{mg} / \mathrm{kg})$ for days $0-3$. Values were shown as the means $\pm \mathrm{SEM}, \mathrm{n}=8$ for each group. $* * P<0.01$ vs control group, ${ }^{\# \#} P<0.01$ vs mice treated with TNBS alone.

Intracellular MPO has prominent effects in destruction of microorganisms, however, its release in extracellur matix may lead to the damage of host tissues with inflammation ${ }^{21,22}$. MPO is a well-established biomarker of neutrophil infiltration for evaluating inflammation in humans and animal model of IBD ${ }^{23-26}$. In our study, AL-1 significantly inhibited the increased MPO activity induced by TNBS in mice. Likewise, histopathological changes which represent the crypt loss and substantial leukocyte infiltration, showed a profile similar to the change of MPO activity in different groups.

Recent genetic and immunological studies have shown that the involvement of cytokines (TNF- $\alpha$, IL- $1 \beta$ and IL-6) contributed to IBD perpetuation and tissue destruction ${ }^{27-29}$. Therefore, that anti-cytokine therapies involving anti-TNF- $\alpha$ agent is now commonly used for IBD in the clinic indicates cytokine inhibitor will be a significant field of interest for IBD therapy ${ }^{30}$. Therefore, anti-cytokine prescription might pave the way to more effective clinical approaches that targets multi-cytokines blocker that could suppress several cytokines simultaneously ${ }^{29}$. Our data indicated that AL-1 could simultaneously inhibit the expression of TNF- $\alpha$, IL-1 $\beta$ and IL- 6 .

The overwhelming activation of NF- $\kappa$ B would aggravate the severity of intestinal inflammation in IBD patients $^{31}$. Therefore blockade of NF- $\kappa B$ activation became a promising therapeutic strategy in IBD ${ }^{31,32}$. The phosphorylation of $\mathrm{p} 65$ and $\mathrm{I} \kappa \mathrm{B} \alpha$ which initiate the activation of NF- $\kappa \mathrm{B}$ are the key regulators in the NF- $\kappa \mathrm{B}$ pathway. In this regard, we wondered whether AL-1 inhibited NF- $\kappa B$ activation to exert its protective effect in TNBS induced mice colitis. We discovered that AL-1 markedly down-regulated the expression of p-p65 and p-I $\kappa \mathrm{B}$ proteins in the experimental colitis. As anticipated, the elevation COX-2 which is regulated by NF- $\kappa B$ in colitis mice could be restored by AL- 1 administration. There is a negative correlative between NF- $\kappa$ B and PPAR- $\gamma$ which is an upstream target of NF- $\kappa B^{33,34}$. In our study, the expression of PPAR- $\gamma$ was markedly increased in AL- 1 treated groups. These results suggested that the effect of AL-1 protecting mice from TNBS-induced colonic injury was very likely mediated by activation of PPAR- $\gamma$.

In summary, morphometric and histological indices of colitis revealed the protective effect of AL-1 in TNBS induced colitis. Furthermore, AL-1 could ameliorate the experimental colitis by regulating NF- $\kappa$ B and PPAR- $\gamma$ signaling pathway. Our study demonstrated that AL-1 might be a promising therapeutic agent of IBD in future.

\section{Materials and Methods}

Regents. AL-1 was previously synthesized and purified in our laboratory. Trinitrobenzenesulfonic acid (TNBS) was purchased from Sigma-Aldrich (St. Louis, MO). Kits for determining myeloperoxidase (MPO) and ELISA kits for TNF- $\alpha$, IL- $1 \beta$ and IL- 6 were purchased from Nanjing Jiancheng Bioengineering Institute (Nanjing, China). Antibodies against p65, p-p65, I $\kappa \mathrm{B} \alpha, \mathrm{p}-\mathrm{I} \kappa \mathrm{B} \alpha, \mathrm{COX}-2$ and PPAR- $\gamma$ were purchased from Cell Signaling Technology Inc (Boston, MA). Antibodies against p50 and $\beta$-actin were purchased from Abcam (Cambridge, MA, USA). All other reagents were obtained from Sigma Chemical Co. (St. Louis, MO).

Animals. C57BL/6 (aged 6-8 weeks) were purchased from Guangdong Medical Laboratory Animal Center (Guangzhou, China). The mice were kept in the temperature controlled room with $12 \mathrm{~h}$ dark/light cycles, and were allowed free food and water ad libitum. All animal welfare and experimental procedures were approved by 


\begin{tabular}{|l|c|}
\hline Colon damage & score \\
\hline No damage & 0 \\
\hline Hyperemia without ulcers & 1 \\
\hline Hyperemia and wall thickening without ulcers & 2 \\
\hline One ulceration site without wall thickening & 3 \\
\hline Two or more ulceration sites & 4 \\
\hline $0.5 \mathrm{~cm}$ extension of inflammation or major damage & 5 \\
\hline $1 \mathrm{~cm}$ extension of inflammation or severe damage & $6-10$ \\
\hline
\end{tabular}

Table 1. Evaluation of macroscopic scores. The score was increased by 1 for every $0.5 \mathrm{~cm}$ of damage up to a maximal score of 10 .

\begin{tabular}{|l|c|c|c|}
\hline DAI score & Weight loss $\mathbf{( \% )}$ & Stool consistency & Occult/gross bleeding \\
\hline 0 & None & Normal & Normal \\
\hline 1 & $1-5$ & & \\
\hline 2 & $5-10$ & Loose stools & Hemoccult positive \\
\hline 3 & $10-15$ & & \\
\hline 4 & $>15$ & Diarrhea & Gross bleeding \\
\hline
\end{tabular}

Table 2. Evaluation of disease activity index (DAI). DAI was determined by combining scores of body weight loss, stool consistency and Gross bleeding.

the Research Ethics Committee of Jinan University. In addition, animal experiments were performed in accordance with relevant guidelines and regulations.

Induction of colitis and treatments. Colitis was induced in accordance with the method as described previously ${ }^{35}$. Briefly, animals were fasted for $18-24$ hours with free access to $5 \%$ glucose solution. Subsequently, mice were anaesthetized by inhaling diethyl ether. Mice were randomly assigned into control and colitis groups. A medical grade catheter was gently inserted into colon ( $4 \mathrm{~cm}$ proximal to the anus). In order to induce colitis, TNBS ( $100 \mathrm{mg} / \mathrm{kg}, 50 \%$ ethanol solution) was slowly instilled into colon. A head down position was applied to ensure TNBS fully distributed in the entire colon for $3 \mathrm{~min}$. The control group received $100 \mu \mathrm{l}$ of $50 \%$ ethanol alone through the same technique. The animals were then given free access to food and water. Throughout the experiments, mice were monitored for body weight loss. At 72 hour following TNBS administration, the animals were killed, and the colon was removed, dissected and opened lengthwise.

To evaluate the therapeutic effect of AL- 1 in experimental colitis, animals were administered orally with different doses of AL- 1 twice a day $(5,15$ and $45 \mathrm{mg} / \mathrm{kg}) 3 \mathrm{~h}$ before TNBS instillation. AL- 1 was suspended in $5 \%$ polyvinyl alcohol 17-88 solution which contain 1\% 1, 3-Propanediol, 1\% Tween 80 and 1\% ethanol. The same solvent was given to both the control and model groups. Mesalazine was used as a positive control and given to the animals with induced colitis at a dose of $100 \mathrm{mg} / \mathrm{kg}$ daily, i.g.

Evaluation of macroscopic scores. Evaluation pattern for macroscopic characteristics was determined by previously established scoring system (Table 1$)^{36}$.

Evaluation of disease activity index (DAI). Evaluation pattern for disease activity was determined by previously established scoring system (Table 2$)^{37}$.

Histopathological examination. Colon tissues were collected and fixed into $4 \%$ buffered formaldehyde solution overnight at $4{ }^{\circ} \mathrm{C}$. The fixed tissues were cut into small sizes and put in a labelled tissue cassette for dehydration processing. The tissues were cleaned twice with xylene before being embedded in paraffin. Paraffin sections were cut into slices of $4 \mu \mathrm{m}$ and stained with H\&E staining solution. Finally, the stained sections were observed and photographed under a light microscope (with $100 \times$ magnification). Colon mucosa damage index scoring was assessed in a blinded fashion as described in Table $3^{38}$.

Determination of inflammatory cytokine levels. Serum was collected from blood of mice by centrifuge at $3500 \mathrm{~g}$ for $15 \mathrm{~min}$. Serum cytokine levels were measured by specific ELISA kits from Nanjing Jiancheng Bioengineering Institute.

Myeloperoxidase (MPO) assay. Protein extracted from colonic tissue was used to determined MPO level according to manufacturer's instructions. The results were expressed as activity units per mg tissue.

Western blot assay. To investigate the mechanism of AL-1 improved colitis induced by TNBS, we examined the effect of AL- 1 on the expression of COX-2, NF- $\kappa$ B and PPAR- $\gamma$ by western blotting. Protein from colonic tissue was extracted in lysis buffer. The protein concentration was then measured using a BCA Protein Assay kit (Pierce Biotechnology, Rockford, IL, USA). Equal amounts of protein $(20 \mu \mathrm{g})$ were boiled with loading buffer for $10 \mathrm{~min}$. The protein extracts were subjected to electrophoresis on SDS-PAGE gel and then transferred to a 


\begin{tabular}{|l|c|}
\hline Colon mucosa damage & Score \\
\hline Inflammatory cells & 0 \\
\hline Presence of occasional inflammatory cells in the lamina propria & 1 \\
\hline Increased numbers of inflammatory cells in the lamina propria & 2 \\
\hline Confluence of inflammatory cells, extending into the submucosa & 3 \\
\hline Transmural extension of the infiltrate & 0 \\
\hline Tissue damage & 1 \\
\hline No mucosal damage & 2 \\
\hline Discrete lymphoepithelial lesions & 3 \\
\hline Surface mucosal erosion or focal ulceration & \\
\hline Extensive mucosal damage and extension into deeper structures of the bowel wall & \\
\hline
\end{tabular}

Table 3. Evaluation of Colon mucosa damage index. The combined histological score ranged from 0 (no changes) to 6 (extensive cell infiltration and tissue damage).

nitrocellulose membrane. The membranes were incubated with skim milk (5\%) for $1 \mathrm{~h}$ at room temperature and then with primary antibodies overnight at $4{ }^{\circ} \mathrm{C}$, followed by incubation with corresponding secondary antibodies. The signals were developed by using an ECL western blot detection kit and visualized on the Carestream molecular imaging system.

Statistical analysis. The experimental data are expressed as the mean \pm standard deviation. One-way analysis of variance (ANOVA) and LSD tests were used to make comparisons among the groups using SPSS 17.0 statistical software. Differences of $P<0.05$ were considered statistically significant.

\section{References}

1. Ananthakrishnan, A. N. Epidemiology and risk factors for IBD. Nature reviews. Gastroenterology \& hepatology 12, 205-217, doi: 10.1038/nrgastro.2015.34 (2015).

2. Cosnes, J., Gower-Rousseau, C., Seksik, P. \& Cortot, A. Epidemiology and natural history of inflammatory bowel diseases. Gastroenterology 140, 1785-1794, doi: 10.1053/j.gastro.2011.01.055 (2011).

3. Molodecky, N. A. et al. Increasing incidence and prevalence of the inflammatory bowel diseases with time, based on systematic review. Gastroenterology 142, 46-54 e42, quiz e30, doi: 10.1053/j.gastro.2011.10.001 (2012).

4. Maloy, K. J. \& Powrie, F. Intestinal homeostasis and its breakdown in inflammatory bowel disease. Nature 474, 298-306, doi: 10.1038 /nature10208 (2011).

5. Frosali, S. et al. How the Intricate Interaction among Toll-Like Receptors, Microbiota, and Intestinal Immunity Can Influence Gastrointestinal Pathology. Journal of immunology research 2015, 489821, doi: 10.1155/2015/489821 (2015).

6. Atreya, I., Atreya, R. \& Neurath, M. F. NF-kappaB in inflammatory bowel disease. Journal of internal medicine 263, 591-596, doi: 10.1111/j.1365-2796.2008.01953.x (2008).

7. Poliska, S. et al. Association of peroxisome proliferator-activated receptor gamma polymorphisms with inflammatory bowel disease in a Hungarian cohort. Inflammatory bowel diseases 18, 472-479, doi: 10.1002/ibd.21798 (2012).

8. Gasparini, C. \& Feldmann, M. NF-kappaB as a target for modulating inflammatory responses. Current pharmaceutical design 18, 5735-5745 (2012).

9. Langmead, L., Chitnis, M. \& Rampton, D. S. Use of complementary therapies by patients with IBD may indicate psychosocial distress. Inflammatory bowel diseases 8, 174-179 (2002).

10. Dahmen, U. et al. Boswellic acid, a potent antiinflammatory drug, inhibits rejection to the same extent as high dose steroids. Transplantation proceedings 33, 539-541 (2001).

11. Nancey, S. et al. Tumor necrosis factor alpha reduces butyrate oxidation in vitro in human colonic mucosa: a link from inflammatory process to mucosal damage? Inflammatory bowel diseases 11, 559-566 (2005).

12. Wiart, C. et al. Antiviral properties of ent-labdene diterpenes of Andrographis paniculata nees, inhibitors of herpes simplex virus type 1. Phytotherapy research: PTR 19, 1069-1070, doi: 10.1002/ptr.1765 (2005).

13. Abu-Ghefreh, A. A., Canatan, H. \& Ezeamuzie, C. I. In vitro and in vivo anti-inflammatory effects of andrographolide. International immunopharmacology 9, 313-318, doi: 10.1016/j.intimp.2008.12.002 (2009).

14. Chan, S. J., Wong, W. S., Wong, P. T. \& Bian, J. S. Neuroprotective effects of andrographolide in a rat model of permanent cerebral ischaemia. British journal of pharmacology 161, 668-679, doi: 10.1111/j.1476-5381.2010.00906.x (2010).

15. Li, Y. et al. Andrographolide derivative AL-1 improves insulin resistance through down-regulation of NF-kappaB signalling pathway. British journal of pharmacology 172, 3151-3158, doi: 10.1111/bph.13118 (2015).

16. Liu, W. et al. Andrographolide sulfonate ameliorates experimental colitis in mice by inhibiting Th1/Th17 response. International immunopharmacology 20, 337-345, doi: 10.1016/j.intimp.2014.03.015 (2014).

17. Sun, J., Zhang, H., Guan, L., Zhou, H. \& Sun, M. Alpha-lipoic acid attenuates trinitrobenzene sulfonic acid-induced ulcerative colitis in mice. International journal of clinical and experimental medicine 8, 358-367 (2015).

18. Kolgazi, M., Jahovic, N., Yuksel, M., Ercan, F. \& Alican, I. Alpha-lipoic acid modulates gut inflammation induced by trinitrobenzene sulfonic acid in rats. Journal of gastroenterology and hepatology 22, 1859-1865, doi: 10.1111/j.1440-1746.2006.04504.x (2007).

19. Trivedi, P. P. \& Jena, G. B. Role of alpha-lipoic acid in dextran sulfate sodium-induced ulcerative colitis in mice: studies on inflammation, oxidative stress, DNA damage and fibrosis. Food and chemical toxicology: an international journal published for the British Industrial Biological Research Association 59, 339-355, doi: 10.1016/j.fct.2013.06.019 (2013).

20. Yan, H. et al. Protective effects of andrographolide derivative AL-1 on high glucose-induced oxidative stress in RIN-m cells. Current pharmaceutical design (2015).

21. Bradley, P. P., Christensen, R. D. \& Rothstein, G. Cellular and extracellular myeloperoxidase in pyogenic inflammation. Blood 60, 618-622 (1982).

22. Klebanoff, S. J. Myeloperoxidase: friend and foe. Journal of leukocyte biology 77, 598-625, doi: 10.1189/jlb.1204697 (2005).

23. Lee, I. A., Park, Y. J., Yeo, H. K., Han, M. J. \& Kim, D. H. Soyasaponin I attenuates TNBS-Induced colitis in mice by inhibiting NFkappaB pathway. Journal of agricultural and food chemistry 58, 10929-10934, doi: 10.1021/jf102296y (2010). 
24. Fitzpatrick, L. R. et al. 4SC-101, a novel immunosuppressive drug, inhibits IL-17 and attenuates colitis in two murine models of inflammatory bowel disease. Inflammatory bowel diseases 16, 1763-1777, doi: 10.1002/ibd.21264 (2010).

25. Abad, C. et al. Therapeutic effects of vasoactive intestinal peptide in the trinitrobenzene sulfonic acid mice model of Crohn's disease. Gastroenterology 124, 961-971, doi: 10.1053/gast.2003.50141 (2003).

26. Santucci, L. et al. Galectin-1 suppresses experimental colitis in mice. Gastroenterology 124, 1381-1394 (2003).

27. Strober, W., Fuss, I. J. \& Blumberg, R. S. The immunology of mucosal models of inflammation. Annual review of immunology 20, 495-549, doi: 10.1146/annurev.immunol.20.100301.064816 (2002).

28. Ruffolo, C. et al. Subclinical intestinal inflammation in patients with Crohn's disease following bowel resection: a smoldering fire. Journal of gastrointestinal surgery: official journal of the Society for Surgery of the Alimentary Tract 14, 24-31, doi: 10.1007/s11605009-1070-9 (2010).

29. Moldoveanu, A. C., Diculescu, M. \& Braticevici, C. F. Cytokines in inflammatory bowel disease. Romanian journal of internal medicine $=$ Revue roumaine de medecine interne 53, 118-127 (2015).

30. Danese, S. \& Fiocchi, C. Ulcerative colitis. The New England journal of medicine 365, 1713-1725, doi: 10.1056/NEJMra1102942 (2011).

31. Andresen, L. et al. Activation of nuclear factor kappaB in colonic mucosa from patients with collagenous and ulcerative colitis. Gut 54, 503-509, doi: 10.1136/gut.2003.034165 (2005).

32. Ardite, E. et al. Effects of steroid treatment on activation of nuclear factor kappaB in patients with inflammatory bowel disease. British journal of pharmacology 124, 431-433, doi: 10.1038/sj.bjp.0701887 (1998).

33. Su, C. G. et al. A novel therapy for colitis utilizing PPAR-gamma ligands to inhibit the epithelial inflammatory response. The Journal of clinical investigation 104, 383-389, doi: 10.1172/jci7145 (1999).

34. Nakajima, A. et al. Endogenous PPAR gamma mediates anti-inflammatory activity in murine ischemia-reperfusion injury. Gastroenterology 120, 460-469 (2001).

35. Neurath, M. F., Fuss, I., Kelsall, B. L., Stuber, E. \& Strober, W. Antibodies to interleukin 12 abrogate established experimental colitis in mice. The Journal of experimental medicine 182, 1281-1290 (1995).

36. Morris, G. P. et al. Hapten-induced model of chronic inflammation and ulceration in the rat colon. Gastroenterology 96, 795-803 (1989).

37. Alex, P. et al. Distinct cytokine patterns identified from multiplex profiles of murine DSS and TNBS-induced colitis. Inflammatory bowel diseases 15, 341-352, doi: 10.1002/ibd.20753 (2009).

38. Siegmund, B. et al. Neutralization of interleukin-18 reduces severity in murine colitis and intestinal IFN-gamma and TNF-alpha production. American journal of physiology. Regulatory, integrative and comparative physiology 281, R1264-R1273 (2001).

\section{Acknowledgements}

This work was supported in part by grants from the Science and Technology Planning Project of Guangdong Province, China (2015B020211011) and the National Natural Science Foundation of China (81001683 and U1032007).

\section{Author Contributions}

Y.Y. performed the animal experiments and wrote the first draft of the paper. H.Y. performed the animal experiments. M.J. carried out the experiments involving Myeloperoxidase assay and western blot analysis. Z.Z., G.Z. and L.S. assessed the results and performed the statistical analyses. Y.S. and P.Y. contributed to discussion and technical guidance or assistance. Y.W. and L.X. conceived, guided and supported experiments, assessed the results and gave the final version of the paper. All authors read and approved the paper.

\section{Additional Information}

Competing financial interests: The authors declare no competing financial interests.

How to cite this article: Yang, Y. et al. Andrographolide derivative AL-1 ameliorates TNBS-induced colitis in mice: involvement of NF-KB and PPAR- $\gamma$ signaling pathways. Sci. Rep. 6, 29716; doi: 10.1038/srep29716 (2016).

(c) (i) This work is licensed under a Creative Commons Attribution 4.0 International License. The images or other third party material in this article are included in the article's Creative Commons license, unless indicated otherwise in the credit line; if the material is not included under the Creative Commons license, users will need to obtain permission from the license holder to reproduce the material. To view a copy of this license, visit http://creativecommons.org/licenses/by/4.0/ 